\title{
Retraction Note to: CXCL12/CXCR4 Axis Upregulates Twist to Induce EMT in Human Glioblastoma
}

\author{
Chengjun $\mathrm{Yao}^{1} \cdot$ Panpan $\mathrm{Li}^{2} \cdot$ Huishu Song ${ }^{2} \cdot$ Fuxi Song ${ }^{2}$. \\ Yalan $\mathrm{Qu}^{2} \cdot$ Xiaochen $\mathrm{Ma}^{2} \cdot$ Ranran $\mathrm{Shi}^{2} \cdot$ Jinsong $\mathrm{Wu}^{1}$
}

Published online: 26 May 2017

(C) Springer Science+Business Media New York 2017

Retraction Note to: Mol Neurobiol (2016) 53:3948-3953

DOI 10.1007/s12035-015-9340-x

This article has been retracted at the request of the Editorin-Chief and the Publisher per the Committee on Publication Ethics guidelines. The article shows evidence of irregularities in authorship during the submission process, there is strong reason to believe that the peer review process was compromised and the authors have plagiarized parts from the following article:

Guosong Li, Yanjun Yang, Siliang Xu, Lifeng Ma, Mingtang He, Ziqing Zhang, Slug signaling is upregulated by CCL21/CXCR7 to induce EMT in human chondrosarcoma, Medical Oncology February 2015, 32:2, DOI: 10.1007/s12032-014-0478-6; Received: 18 December 2014

As such the validity of the content of this article cannot be verified.

The online version of the original article can be found at http://dx.doi.org/ $10.1007 / \mathrm{s} 12035-015-9340-\mathrm{x}$

Jinsong $\mathrm{Wu}$

wujssh@126.com

1 Glioma Surgery Division, Neurological Surgery Department, Huashan Hospital, Shanghai Medical College, Fudan University,

12ti, Wulumuqi Zhong Road, Shanghai 200040, China

2 School of Medicine, Qilu Hospital, Shandong University,

Jinan, Shandong, China 